\title{
Bacteriological profile of pharmaceutical water used for production purpose
}

\begin{abstract}
Objectives: To determine the bacteriological quality of pharmaceutical water used for production purposes (cosmetics, medicine, etc.).

Materials and methods: An experimental study was conducted of 20 pharmaceutical water samples, collected from reputed pharmaceutical companies located in Peshawar, Pakistan. To enumerate the overall microbial load and particular pathogens from the obtained water samples traditional culture and biochemical approaches were used.
\end{abstract}

Results: A total aerobic viable bacterial load of all samples were found below the acceptable limit (200 CFU/mL) while, Pseudomonas species were found (n=03), and Escherichia coli was found $(\mathrm{n}=01)$. No evidence of Staphylococcus aureus and Salmonella species were found in any of the samples.

Conclusion The current study provides a comprehensive bacteriological profile of pharmaceutical water and demonstrates that the presence of particular bacteria might cause significant toxicity and hazard in final pharmaceutical products.

Keywords: pharmaceutical water, bacteriological profile, medicine preparation
Volume 5 Issue 5 - 202I

\author{
Syed Hussain Shah, ${ }^{1,2}$ Muddasir Khan, ${ }^{3,4}$ \\ Abdullah,' Aziz Ur Rehmnan, ${ }^{4}$ Muhammad \\ Atif $^{4}$ \\ 'Department of Health and Biological Sciences, Abasyn \\ University Peshawar, Pakistan \\ ${ }^{2}$ Alliance Pharmaceutical Industry, Hayatabad Industrial State \\ Peshawar, Pakistan \\ ${ }^{3}$ Center of Biotechnology and Microbiology, University of \\ Peshawar, Pakistan \\ ${ }^{4}$ Hicon Pharmaceutical Industry, Hayatabad Industrial State \\ Peshawar, Pakistan
}

Correspondence: Muddasir Khan, Center of Biotechnology and Microbiology, University of Peshawar, Pakistan, Email mk03025678947@gmail.com,

muddasir.khan0302@gmail.com

Received: November 15, 2021 | Published: November 30, 2021

\section{Introduction}

Water plays a key role in pharmaceutical and life science industries such as; used as an ingredient, solvent, raw material, manufacturing, processing of products, and active pharmaceutical ingredients. This water must meet quality standards established either by European Pharmacopeia(EP), United States Pharmacopeia (USP), British Pharmacopeia (BP), and other organizations. ${ }^{1}$ Pharmaceutical grade water has undergone a chemical purification procedure is required for these purposes, which ensures that the water is free of pollutants might interfere with prescription components, as well as that it fulfills a microbiological requirement.

Microorganism's ability to thrive and flourish under a variety of conditions is broad and diversified, aggravating flaws in water systems. As a result, monitoring bio-burden levels in pharmaceuticalgrade water systems is important. The two major types of water in the pharmaceutical concerned are; purified water and water for injections (WFI).That both types of water need bio-burden assessment, with addition WFI need bacterial endotoxin testing as well. ${ }^{2}$ In the pharmaceutical industry, there are even fewer published references on the expected microorganisms in treated water.

Therefore, the current study was aimed to investigate the bacteriological profile of the pharmaceutical water, used in product preparation.

\section{Material and methods}

\section{Study design}

An experimental study was conducted from November 2020 to April 2021 at the Department of Microbiology, Alliance Pharmaceuticals Industry (PVT) LTD, Peshawar, Pakistan.

\section{Samples collection}

A total of 20 samples were obtained from the purified water systems from various production areas in a sterile plastic container.

\section{Microbiale numeration}

The overall microbial load was counted using the membrane filtration method. The filter paper was taken aseptically from the filter unit after the water had been filtered and placed on the Nutrient agar media and incubated for 3 days at $30-35^{\circ} \mathrm{C} .{ }^{3}$

\section{Examination of pathogenic bacteria}

For the examination of pathogenic bacteria, $100 \mathrm{~mL}$ of water sample pass through a $0.45 \mu \mathrm{m}$ membrane filter. The membrane filter is incubated for 24 hours at $30-35{ }^{\circ} \mathrm{C}$ in a $100 \mathrm{~mL}$ sterile soybean casein digest medium. To identify Escherichia coli, smear a portion of rich soybean casein digest media over the surface of sterile MacConkey agar medium. Incubate the plates at $30-35^{\circ} \mathrm{C}$ for $18-72$ hours. After incubation, the development of brick red colonies on MacConkey agar confirms the presence of Escherichia coli. Furthermore, streaking of the colonies on the surface of Levine eosin methylene blue agar medium, the development of blue-black colonies with a metallic sheen confirms the presence of $E$. coli. To detect the presence of Staphylococcus aureus, the filter paper was placed on a mannitol salt agar (MSA) plate and incubated at $30-35^{\circ} \mathrm{C}$ for $18-72$ hours. In appearance, the yellowish-white colonies surrounded by a yellow zone were S.aureus positive.To identify Salmonella species, add 0.1 $\mathrm{ml}$ of enriched soybean casein digest medium to $10 \mathrm{ml}$ of Rappaport Vassiliadis Salmonella enrichment broth and incubate at $30-35^{\circ} \mathrm{C}$ for 24-48 hours. With a streak of above media on the surface of Wilson and Blairs' agar plate, incubate at $30-35^{\circ} \mathrm{C}$ for $24-48$ hours. Green colonies with a black center develop, and the colonies are uniformly 
black after 48 hours. If colonies are bordered by a black zone and have a metallic sheen, Salmonella may be present. Incubate for 24-48hours at $30-35^{\circ} \mathrm{C}$ if sub-cultured on a xylose-lysine-deoxycholate. Welldeveloped red colonies with or without a black center can be used to detect Salmonella. Inoculate the surface of the slant first, then create a stab culture with the same inoculating needle and inoculate a tube of urea broth at the same time to confirm the colonies on the surface of triple sugar-iron agar. Incubate for 18 to 24 hours at 30-35 degrees Celsius. The formation of acid and gas in the stab culture, as well as the lack of acidity from surface growth in the triple sugar iron agar and the absence of red color in the urea broth, indicate the presence of Salmonella. To identify, Pseudomonas aeruginosa cetrimide agar medium was used, which was indicated by a colony that is greenish in appearance. Pigment and oxidase tests should be used to confirm your findings. Streak typical suspicious colonies from the surface of cetrimide agar onto the surface of Pseudomonas agar medium for fluorescence detection, and from the surface of Pseudomonas agar media for pyocyanin detection. Incubate for at least 3 days at 30$35^{\circ} \mathrm{C}$ after covering and inverting the infected plate. Examine the streaked surface in ultraviolet light. Colonies should be identified by looking at the plates. Spread 2 or 3 drops of a freshly prepared $01 \%$ $\mathrm{w} / \mathrm{v}$ solution of tetramethyl-4-phenylenediamine dihydrochloride on filter paper with the colony if suspicious colonies form; if no pink color develops and does not change to purple, the sample meets the criteria. Pseudomonas aeruginosa is not present in the test results. ${ }^{4}$

\section{Results and discussion}

Water is used in the pharmaceutical industry, as well as medical, to make medicines and injectable liquids. To keep medicine production facilities running and assure final product quality, pharmaceuticalgrade water systems must be developed, managed, and maintained. Inadequately maintained and operated systems are regularly identified as a key concern during FDA and other regulatory inspections. Maintenance and operations are not tasks that should be ignored. ${ }^{5}$ Pharmaceutical water systems must be established and controlled uniformly, requiring system validation to ensure operational stability and quantitative monitoring of microbiological characteristics against specified alert and action thresholds to provide an early indication of system control.

All of the samples tested in this study had a total aerobic viable bacterial load below the required limit (i.e., less than 200CFU/mL). Pseudomonas spp. were found in three samples, sample 12, sample 15, and sample 19 (Table 1). Only one sample (Sample no. 4) was found to be E.coli proliferating. In our investigation, however, no evidence of S.aureus was found in any of the samples. In addition, no Salmonella spp. were detected in any of the samples (Table 1). Even if the total bacterial load was within acceptable limits, the presence of certain pathogens in final pharmaceutical products might cause significant toxicity. ${ }^{4}$

Table I Bacteriological enumeration and pathogen in the tested water samples

\begin{tabular}{|c|c|c|c|c|c|}
\hline Sample No. & $\begin{array}{l}\text { Total aerobic microbial } \\
\text { count }(\mathrm{CFU} / \mathrm{ml})\end{array}$ & Escherichia coli & $\begin{array}{l}\text { Staphylococcus } \\
\text { aureus }\end{array}$ & Salmonella species & Pseudomonas species \\
\hline I & 15 & - & - & - & - \\
\hline 2 & 09 & - & - & - & - \\
\hline 3 & 05 & - & - & - & - \\
\hline 4 & 10 & + & - & - & - \\
\hline 5 & 03 & - & - & - & - \\
\hline 6 & 06 & - & - & - & - \\
\hline 7 & 08 & - & - & - & - \\
\hline 8 & 07 & - & - & - & - \\
\hline 9 & 19 & - & - & - & - \\
\hline 10 & 17 & - & - & - & - \\
\hline II & 04 & - & - & - & - \\
\hline 12 & 32 & - & - & - & + \\
\hline 13 & 14 & - & - & - & - \\
\hline 14 & 12 & - & - & - & - \\
\hline 15 & 18 & - & - & - & + \\
\hline 16 & 14 & - & - & - & - \\
\hline 17 & 25 & - & - & - & - \\
\hline 18 & 16 & - & - & - & - \\
\hline 19 & 18 & - & - & - & + \\
\hline 20 & 32 & - & - & - & - \\
\hline
\end{tabular}

$(+)$ indicate Presence of bacteria, (-) indicate an absence of bacteria 


\section{Conclusion}

In conclusion, the bacterial load in all water samples used by pharmaceutical companies to manufacture medicine and pharmaceuticals was below the acceptable limit $(200 \mathrm{CFU} / \mathrm{mL})$, but the presence of certain pathogens in final pharmaceutical products might cause significant toxicity. As the pharmaceutical sector in Pakistan grows, it is critical to analyze, not only the raw materials used in manufacturing but also the microbiological features of the water to ensure the safety of the end product, which will aid public health management. Water used in pharmaceuticals should be checked regularly.

\section{Conflicts of interest}

The authors declare no conflict of interest.

\section{Acknowledgments}

None.

\section{Funding}

None.

\section{References}

1. Shukshith KS, Vishal Gupta N. Water for Pharmaceutical Use. International Journal of Pharmaceutical Sciences Review and Research. 2015;36:199-204.

2. Cundell A, Gordon O, Haycocks N, et al. Novel concept for online water bioburden analysis: key considerations, applications, and business benefits for microbiological risk reduction. American Pharmaceutical Review. 2013;16(4):26-31.

3. Casas DE, Vargas DA, Randazzo E, et al. In-Plant Validation of Novel On-Site Ozone Generation Technology (Bio-Safe) Compared to Lactic Acid Beef Carcasses and Trim Using Natural Microbiota and Salmonella and E. coli O157: H7 Surrogate Enumeration. Foods. 2021;10(5):1002.

4. Khanom SA, Das KK, Banik SO, Noor RA. Microbiological analysis of liquid oral drugs available in Bangladesh. Int J Pharm Pharma Sci. 2013;5(4):479-82.

5. Ramyasree M, Gangadharappa HV, Deepak AM. Review article water for pharmaceutical use. World Journal of Pharmaceutical Research. 2018;7(10):147-60. 